\title{
Autoantigens in primary biliary cirrhosis
}

\author{
D E J Jones
}

\begin{abstract}
The automimmune liver disease primary biliary cirrhosis (PBC) is characterised by serum autoantibodies directed at mitochondrial and nuclear antigens (seen in most patients and a subset of patients, respectively). The antimitochondrial antibodies (AMA) characteristic of PBC are directed at members of the 2-oxoacid dehydrogenase components of multienzyme complexes; in particular, the E2 and E3 binding protein (E3BP) components of the pyruvate dehydrogenase complex (PDC). The presence of autoantibodies reactive with PDC-E2 and/or E3BP is strongly predictive of the presence of PBC. Therefore, the detection of these antibodies plays a very important role in the diagnosis of PBC. Originally demonstrated using immunofluorescence approaches, AMA can now be detected by the use of commercially available enzyme linked immunosorbent assays (ELISAs). Although the ELISA based approaches have advantages in terms of laboratory practicality, they are slightly less sensitive for the diagnosis of PBC than immunofluorescence (occasional patients with PBC show reactivity with PDC related antigens not present in the antigen preparations available for use with ELISA). Therefore, immunofluorescence should continue to be available as a complementary diagnostic test for use in occasional patients. In a subset of patients with PBC, autoantibodies are directed at increasingly well characterised nuclear antigens. Antinuclear antibody (ANA) positive patients are typically AMA negative. There are no significant differences in disease phenotype between AMA positive and AMA negative groups. At present, the clinical detection of ANA is mostly by Hep2 immunofluorescence, although ELISA kits for individual nuclear antigens are increasingly becoming available. (f Clin Pathol 2000;53:813-821)
\end{abstract}

Keywords: liver cirrhosis; biliary; autoimmunity; autoantibody

Centre for Liver Research, 4th Floor William Leech

Building, The Medical School, Framlington

Place, Newcastle upon Tyne NE2 4HH, UK D E J Jones

Correspondence to: Dr Jones

D.E.J.Jones@ncl.ac.uk

Accepted for publication 23 February 1999 previously been realised. ${ }^{3}$ The most recer estimates suggest that it affects up to one in 700 women over the age of $40 .^{3}$ It is increasingly
Primary biliary cirrhosis (PBC) is a chro Recent epidemiological studies have suggested that PBC, which typically, although not exclusively, affects middle aged women, is a much more common clinical problem than had evident that PBC is an important cause of morbidity and mortality in the affected population. Over $80 \%$ of patients are symptomatic (the most pervasive symptoms being fatigue and pruritus), ${ }^{45}$ whereas progression of the disease to cirrhosis, with associated complications including variceal haemorrhage, contributes to the greatly increased standardised mortality ratio seen in patients with PBC. ${ }^{4}$

Recent years have seen important advances in the treatment of PBC. For patients with end stage disease, orthotopic liver transplantation is highly effective, with patients reporting good quality of life postoperatively. ${ }^{7}{ }^{8}$ Reversal of the histological features of PBC (or at least slowing down of the progression of disease), thereby reducing the symptomatic burden, and the risk to life and requirement for transplantation that are associated with advancing disease, remains the goal of medical treatment. The hydrophilic bile acid ursodeoxycholic acid (UDCA), given orally, has been shown to be effective in slowing disease progression and has entered widespread clinical use. ${ }^{9-12}$ It is likely, however, that UDCA is most effective when given early in the disease course. The importance of early treatment emphasises the necessity of early diagnosis. Fortunately, the autoimmune nature of PBC, and the specificity of its characteristic autoantibodies, are now well established. What is perhaps less well appreciated, however, is the sheer strength of the serological associations in PBC, and the resulting power of autoantibody screening in isolation as a diagnostic test for this disease. The purpose of this leader is to review the current data regarding the autoimmune response and its diagnostic detection in PBC, with emphasis on clinical applications. I will discuss each of the major PBC autoantigen families in turn outlining the nature of the antigen, the nature of the immune response mounted to it, and the clinical applications and relevance of detecting this response.

The M2 mitochondrial autoantigens

NATURE OF THE ANTIGEN(s)

It has been appreciated since the 1960s that most patients with PBC have high titres of antibodies in their serum reactive with nonorgan, non-species specific antigens present within mitochondria. ${ }^{13}$ The detection of these antimitochondrial antibodies (AMA) using immunofluorescence remains one of the most important diagnostic tests for PBC. Subsequent experimental approaches further localised the mitochondrial antigens to the inner mitochondrial membrane (and the M2 mitochondrial subfraction) ${ }^{15} 16$ before, in the late 1980s, Gershwin and colleagues, using patient serum to screen an expression library, identified a cDNA clone encoding the dominant 
mitochondrial antigen. ${ }^{17}$ This antigen was subsequently identified as the dihydrolipoamide acyltransferase (enzyme 2 (E2)) component of the pyruvate dehydrogenase complex (PDC). ${ }^{18}{ }^{19}$ Subsequently, it has been shown by enzyme linked immunosorbent assay (ELISA) and immunoblotting that antibodies reactive with PDC-E2 are present in the serum of 95\% of patients with PBC, ${ }^{18}$ confirming that it is to this antigen that the dominant autoreactive response in PBC is mounted.

PDC is a member of the 2-oxoacid dehydrogenase family of multienzyme complexes, the other members of which are 2-oxoglutarate dehydrogenase complex (OGDC) and branch chain 2-oxoacid dehydrogenase complex (BCOADC). PDC, OGDC, and BCOADC all have fundamental roles in cellular metabolism. ${ }^{20}$ These complexes are highly conserved throughout evolution, and are present in all organisms from rickettsia upwards. ${ }^{21}$ All three complexes share a common structure, with multiple repeats of E1 (2-oxoacid dehydrogenase) and E3 (dihydrolipoamide dehydrogenase) subunits built around an E2 (and in the case of PDC only, $\mathrm{E} 2$ and $\mathrm{E} 3$ binding protein (E3BP)) core. All the component subunits are nuclear encoded, and undergo post-translational transport and active uptake into the mitochondria where complex autoassembly occurs. Some component modification occurs within the mitochondria, most notably the addition of a lipoic acid group to the E2 (and where present E3BP) components. Lipoic acid plays a crucial role in the enzymatic function of each complex.

The E2 chains of PDC, OGDC, and BCOADC share a highly segmented structure. They comprise, from the $\mathrm{N}$-terminus, one to three lipoyl domains, a peripheral subunit binding domain, and a large core forming acyltransferase catalytic domain, all linked together by long (25-30 residues) segments of flexible polypeptide chain rich in alanine and proline. ${ }^{22}$ The three dimensional structures of PDC-E2 of both prokaryotic ${ }^{23}$ and eukaryotic ${ }^{24}$ origin have been determined by means of nuclear resonance spectroscopy. A common structure consisting of two four stranded $\beta$-sheets forming a flattened barrel, with the lipoylation site (a lysine residue physically exposed at the tip of a tight turn in one of the $\beta$-sheets), and the $\mathrm{N}$-terminal and $\mathrm{C}$-terminal residues close together at the other end of the molecule, is seen. Little is known, as yet, regarding the three dimensional structures of the other PDC component subunits.

THE AUTOIMMUNE RESPONSE IN PBC

Although, as will be discussed below, immunofluorescence remains a valuable clinical tool, further characterisation of the antigen specificity of the AMA response in PBC was not possible using this technique. This characterisation was performed using immunoblotting and ELISA to detect responses to purified antigens. Different groups have adopted individual approaches to the purification of antigen for use in these experiments. These divide broadly into recombinant and biochemical purification (from PDC rich tissue) based approaches.
Each approach has advantages and disadvantages, and it must be appreciated that some of the apparent differences in responses described in studies from different groups are merely a result of the different approaches taken to antigen preparation.

Immunoblotting of serum from patients with PBC against biochemically purified, tissue derived PDC showed that $95 \%$ of patients who are AMA positive by immunofluorescence have antibodies reactive with PDC-E2. ${ }^{18}$ Immunoblotting and ELISA of serum from patients with PBC against PDC of human origin has confirmed that these are true antibodies showing reactivity with self antigens. ${ }^{25}$ Antibodies reactive with E3BP (formerly known as protein $\mathrm{X})$ are present in all patients showing reactivity with PDC-E2. ${ }^{18}$ The absence of sequence data related to PDC-E3BP precluding synthesis of recombinant antigen, and the failure of biochemical approaches to separate PDC-E3BP from PDC-E2, have, until recently, prevented the isolation of PDC-E3BP and the characterisation of specific autoreactive responses to it. Thus, almost all work on the dominant autoreactive responses in PBC has been directed at PDC-E2. The recent cloning and expression of human E3BP has allowed this imbalance to be redressed The anti-PDC-E3BP and antiPDC-E2 responses appear to be highly crossreactive, although there is a more extensive distribution of $\mathrm{B}$ cell autoepitopes within PDC-E2 than E3BP (pre-absorption of sera from patients with $\mathrm{PBC}$ with recombinant PDC-E2 totally removes antibodies reactive with recombinant E3BP but not vice versa ${ }^{26}{ }^{27}$ ). The degree of crossreactivity at the B cell level between PDC-E2 and E3BP has meant that serological approaches cannot tell us to which of these antigens the initial breakdown of tolerance occurs (the wider distribution of B cell epitopes within PDC-E2 than E3BP is suggestive (but no more) that tolerance breakdown is initially to an epitope in PDC-E2 that is crossreactive with $\mathrm{E} 3 \mathrm{BP}$, with subsequent epitope spreading to non-crossreactive epitopes). A recent study, demonstrating a complete absence of $\mathrm{T}$ cells in the peripheral repertoires of patients with PBC who are reactive with recombinant human E3BP (in contrast to the responses seen to recombinant PDC-E2 in $>90 \%$ of the same patients) suggests that the breakdown of tolerance is principally, if not entirely, to PDC-E2. ${ }^{28}$

Antibodies reactive with the $\mathrm{E} 1 \alpha$ and $\mathrm{E} 1 \beta$ subunits (which are not crossreactive with PDC-E2 or PDC-E3BP) are seen at lower frequency $(40 \%$ and $10 \%$ of patients with PBC, respectively). ${ }^{29}{ }^{30}$ Antibodies are seen to the E2 components of OGDC and BCOADC in approximately $90 \%$ and $50 \%$ of patients with PBC, respectively. ${ }^{31-33}$ Antibodies are not seen to the E3 subunit common to PDC, OGDC, and BCOADC, and to the E1 subunits of OGDC and BCOADC. OGDC and BCOADC do not have E3BP.

Attempts to map the B cell epitopes within PDC-E2 using different experimental approaches (trypsinated whole PDC-E2, truncated recombinant polypeptide, and sequence 
specific peptides) have generated largely consistent results. The dominant $\mathrm{B}$ cell epitope within PDC-E2 is conformational in nature and spans the inner (of two) lipoic acid binding domains. ${ }^{34-38}$ Significantly lower (100 times) titre responses are seen to the outer lipoyl domain. Responses have not been reported to the other domains of PDC-E2. The lipoic acid attached to the inner lipoyl domain of PDC-E2 itself appears to constitute part of the epitope, the AMA response to lipoylated recombinant PDC-E2 being of significantly higher titre and affinity than that seen to unlipoylated antigen. ${ }^{39}$ The role played by lipoic acid in the B cell autoepitope of PDC-E2 has been confirmed in studies of the antigen specificity of human monoclonal antibodies secreted by hybridomas derived from peripheral blood B cells from patients with PBC. ${ }^{40}$ Two (of five) hydridomas were found to be specific for lipoylated recombinant human PDC-E2 inner lipoyl domain, with no binding being seen to unlipoylated antigen. The other three monoclonal antibodies showed greatly reduced binding to unlipoylated antigen. These findings suggest that the lipoic acid residue forms a part, of variable importance, of the dominant $\mathrm{B}$ cell epitope within PDC-E2. In a proportion of B cells, the lipoic acid constitutes such an important part of the epitope that its absence abrogates antigen-antibody binding. ${ }^{40}$

Less is known about epitope localisation within PDC-E3BP. Although a pronounced response is seen to the lipoic acid binding domain, which shows considerable homology with the inner lipoyl domain of PDC-E2, ${ }^{41}$ some patients also respond to the nonhomologous "catalytic" domain. ${ }^{26}$ The dominant epitopes within OGDC-E2 and BCOADC-E2 appear, as is the case with PDC-E2, to be conformational in nature and to be contained within the lipoic acid binding domain. $^{42}{ }^{43}$ The lipoic acid group appears to constitute part of the dominant B cell epitope within PDC-E3BP, ${ }^{26}$ but not those of OGDC-E2 and BCOADC-E2. ${ }^{42-44}$

Important questions that remain unanswered include the mechanism by which immune self tolerance to ubiquitous and highly conserved antigens such as PDC, OGDC, and BCOADC breaks down, and the reasons why tolerance breakdown to these antigens results in a disease with such a restricted tissue distribution (limited to the biliary, salivary, and lachrymal epithelium). Another important issue requiring clarification is the precise role played by different effector mechanisms in the pathogenesis of target cell damage in PBC and in particular the question of the direct role, if any, played by anti-PDC antibodies. ${ }^{45}$ The observation that placental transfer of IgG antiPDC can occur, and is associated (in two cases at least) with liver damage (albeit not typical PBC) in the baby raises the possibility that anti-PDC antibodies play a direct role in disease pathogenesis. ${ }^{46}$

One observation of potential relevance for our understanding of the tissue tropism of PBC is that the subcellular distribution pattern of PDC is abnormal in PBC, with aberrant cell surface expression of the complex (which is normally exclusively mitochondrial in distribution) being seen in the affected biliary and salivary epithelia. ${ }^{47-52}$ The mechanism giving rise to this aberrant cell surface expression of PDC is unclear, but the end result could be that the cells are vulnerable to antibody dependent pathways of cell cytotoxicity. An alternative potential mechanism whereby anti-PDC antibodies could contribute directly to target cell damage is suggested by the recent observations that IgG antibodies can penetrate living cells and interfere with cellular function. ${ }^{53}$ As yet no data are available regarding the penetration of IgG anti-PDC into epithelial cells and the resulting effects, if any, on cell metabolism function and integrity.

Although data on IgG anti-PDC penetration into epithelial cells in PBC are lacking there is strong, if indirect, evidence to suggest that dimeric IgA anti-PDC can enter and be exported across epithelial cells as part of the normal physiological process of $\operatorname{IgA}$ transcytosis. ${ }^{54}{ }^{55}$ Moreover, in in vitro systems at least, IgA anti-PDC taken up into cultured epithelial cells has been shown to colocalise with PDC-E2 within the cell. ${ }^{56}$ In viral infection model systems, it has been shown previously that IgA specific for viral antigens can, while undergoing transcytosis, bind to viral antigens within infected epithelial cells and export them from the cell. ${ }^{57}$ It has been proposed, therefore, that IgA anti-PDC could, while undergoing transcytosis, bind to nascent PDC component polypeptides and export them from the cell, thereby leading to chronic PDC depletion and metabolic damage to the cell. ${ }^{58}$ This model would, if correct, help to explain both the aberrant expression of PDC on the epithelial cell surface (it is taken there by transcytosing IgA anti-PDC) and the tissue tropism of the disease (it is restricted to those tissues that export IgA by the process of transcytosis). Although this model is intriguing there remains, at present, little hard evidence to support it.

An alternative possibility is that AMA, in fact, play little or no direct role in target cell damage in PBC and are merely an "immunological overspill" phenomenon resulting from the generation of a (increasingly well characterised) $\mathrm{T}$ cell response that is itself responsible for the damage. ${ }^{59-64}$ If autoreactive $\mathrm{T}$ cell responses do indeed play a dominant role in the pathogenesis of PBC it is perhaps surprising that the major histocompatibility complex (MHC) associations seen in the disease are relatively weak. ${ }^{65}$ One potential explanation for this finding comes, however, from the observation that the dominant $\mathrm{T}$ cell autoepitope in PBC contains anchor residues allowing it, theoretically at least, to bind to multiple human MHC (HLA) alleles. ${ }^{63}{ }^{66}$ Data from a recently described mouse model of PBC (experimental autoimmune cholangitis (EAC)), in which sensitisation of SJL/J mice with PDC induces immunological and histological features characteristic of PBC, appear to confirm the view that $\mathrm{T}$ cell mediated responses are responsible for target cell damage. The generation of autoreactive anti-PDC antibodies is a rapid 
and non-specific feature of the sensitisation of mice with PDC, which is non-predictive of the development of bile duct lesions. In contrast, the generation of an autoreactive anti-PDC $\mathrm{T}$ cell response correlates completely with the presence and kinetics of histological damage..$^{5867-69}$

CLINICAL RELEVANCE

In contrast to their uncertain pathophysiological relevance, the importance of anti-M2 AMA as diagnostic markers for PBC cannot be overstated. Anti-M2 AMA are among the most sensitive and specific of all serological disease markers. More than $95 \%$ of patients with liver biopsy and serum liver biochemical (a typically cholestatic pattern) features of PBC will be AMA positive by immunofluorescence, and will have serum anti-PDC antibodies detected by immunoblotting. An ELISA developed by our group (using biochemically purified PDC$\mathrm{E} 2 / \mathrm{E} 3 \mathrm{BP}$ as antigen) has been shown to have a sensitivity of $93 \%$ and a specificity of $96 \%$ for the diagnosis of PBC. ${ }^{70}$ The combination of AMA and cholestatic liver function tests (LFTs) is therefore highly suggestive of the diagnosis if PBC. Liver biopsy is still recommended, however, to confirm the diagnosis and, in particular, to allow histological staging.

The strength of the association between AMA in PBC is such, however, that the presence of the autoantibody in isolation is strongly suggestive of the presence of histological features of PBC in the liver. In 1986, we reported the outcome of investigations performed on a series of patients who were AMA positive, but who had no symptoms suggestive of PBC, and who had normal LFTs. Twenty four of these 29 patients were found to have liver histological features diagnostic of, or compatible with, PBC. ${ }^{71}$ In 1996 , we reported on the outcome of this cohort of patients after follow up of a median of 17.8 years. ${ }^{72}$ Of the original 29 patients, $22(76 \%)$ had developed typical symptoms of PBC and 24 (83\%) had developed abnormal LFTs with a typical cholestatic picture. Interestingly, although five patients had died, none had died of liver related causes, and of the 10 who had undergone a further liver biopsy for clinical reasons, none had developed cirrhosis (stage IV PBC). Therefore, the conclusions from these two studies are that the presence of AMA is strongly suggestive of the presence of histological features of PBC in the liver, even in the absence of symptoms or abnormal LFTs, and that, over time, such patients will go on to develop "classic" clinical PBC. However, patients presenting in this manner appear to have a slowly progressive form of the disease. Our current practice is to monitor annually for LFTs all patients who are AMA positive and have normal LFTs. If, during follow up, patients develop cholestatic LFTs, we would then proceed to liver biopsy to confirm and stage the disease before starting UDCA treatment. We believe that aggressive monitoring of patients with such early disease is warranted because the efficacy of UDCA treatment is highest when started early in the disease process.
It is unclear whether the titre of AMA seen in patients with $\mathrm{PBC}$ has any predictive value for disease severity. One early ELISA study suggested that there was a positive association between disease stage and IgG AMA titre. ${ }^{70}$ This observation appeared to support earlier ones made using indirect immunofluorescence based approaches to IgG AMA detection, which similarly showed increasing AMA titre with advancing disease..$^{73}$ More recently, an association between serum IgA AMA titre and liver inflammatory activity in both the untreated and UDCA treated state has been reported. ${ }^{75} \mathrm{~A}$ further study has, however, failed to show any significant association between AMA titre detected by either immunofluorescence or ELISA and disease severity as assessed by the Mayo score (a well validated disease prognosis model $).^{76} \mathrm{My}$ feeling is that any correlation between AMA titre and disease activity/severity/progression is limited and of no practical relevance in the clinical assessment of patients.

One practical issue in the serological detection of AMA now faced by diagnostic laboratories and clinicians is the choice of assay. Indirect immunofluorescence remains the "gold standard" for the serodiagnosis of PBC (having close to $100 \%$ specificity ${ }^{77}$ ) but is labour intensive and observer dependent. Newer approaches such as ELISA and assays based on the ability of AMA to inhibit the enzymatic function of PDC, a phenomenon that can be relatively easily adapted for use in a colorimetric assay, ${ }^{78-81}$ are less labour intensive. The question is, however, are they as clinically useful? As described above, an ELISA using biochemically purified PDC-E2/E3BP has been shown to be $93 \%$ sensitive and $96 \%$ specific for the diagnosis of PBC. The use of this PDC-E2/E3BP preparation has the advantage that it contains both the major antigenic proteins and retains physiological conformation-important when the dominant epitopes are conformational in nature. The disadvantage of this ELISA is that it requires tissue derived antigen and is thus not practical for widespread laboratory use. Therefore, the use of ELISAs based on recombinant antigens is theoretically attractive. It appears, however, that although the specificity of ELISAs using recombinant antigen can be very impressive, sensitivities can be lower than those reported for immunofluorescence or ELISA using whole antigen. ${ }^{77}{ }^{82}$ The reasons for this lower sensitivity are twofold. First, there is the issue of the conformational nature of the epitopes, reduced or lost in recombinant molecules. Second, there is the problem of the (small) subgroup of patients with clear cut PBC who have AMA that react exclusively with non-PDC-E2 mitochondrial antigens (PDC-E1, PDC-E3BP, OGDC-E2, and BCOADC-E2). Although "designer" recombinant molecules have been synthesised containing OGDC-E2 and BCOADC-E2, in addition to PDC-E2, these cannot be used for patients responsive to PDC-E1 only (up to $2 \%$ of the total PDC population). In the future, PDC function inhibition based assays might be useful to deal with 
this problem. However, at present there are few data pertaining to their use in clinical practice and it is thus too early to draw conclusions regarding their ultimate usefulness.

What then would be the current recommendations for the serodiagnosis of AMA in PBC? For most patients recombinant antigen based ELISAs will detect the presence of AMA perfectly satisfactorily. It is important to remember, however, the possibility of false negative findings resulting from non-PDC-E2 responses or responses to exclusively conformational antigens. Thus, if the clinical suspicion of PBC is high, but the patient is anti-M2 negative by ELISA, indirect immunofluorescence should be used as a back up test.

\section{Nuclear antigens}

Early studies of PBC demonstrated that up to a third of patients with PBC had serum autoantibodies directed against nuclear autoantigens as detected by immunofluorescence. ${ }^{83}$ The identities of the antigens against which the PBC specific antinuclear antibodies (ANA) are directed have been established in recent years and an idea of their clinical relevance obtained. The most clinically relevant observation regarding ANA in PBC is that most of the (small) subgroup of PBC patients who are AMA negative are ANA positive. ${ }^{84} 85$ The current consensus is that the clinical spectrum of the disease, and response to treatment, are broadly similar in classic AMA positive and AMA negative/ ANA positive disease (a variant that has been given the specific name autoimmune cholangitis), and that the two "conditions" merely reflect variants of the same disease process. ${ }^{86}$ Therefore, the importance of detecting PBC related ANA in AMA negative patients is that it enables a broad diagnosis to be made, rather than identifying a subgroup of patients who should receive different treatment or monitoring.

Two typical patterns of nuclear immunofluorescence staining (best described using Hep2 cells rather than the composite tissue blocks used in AMA immunofluorescence) have been described in PBC, one giving a membrane like pattern of staining (M-ANA) and the other staining of multiple nuclear dots (MNDANA). Although, as will be discussed below, ELISA based approaches to the detection of PBC specific ANA have been developed they are not as yet widely available in diagnostic laboratories. Therefore, the gold standard technique for the detection of ANA in PBC remains immunofluorescence using Hep2 cells.

M-ANA

Most of the autoantibodies from patients with PBC that label the nuclear envelope recognise a protein with a molecular mass of about $200 \mathrm{kDa}{ }^{87}{ }^{88}$ This protein has been identified as the nuclear pore membrane glycoprotein gp $210,{ }^{89}$ a finding confirmed by the demonstration that M-ANA recognise recombinant gp210 in an ELISA. ${ }^{90}$ The specificity and sensitivity of anti-gp210 autoantibodies for the diagnosis of PBC were determined in two large series of patients. In a French study, $25 \%$ of patients were found to have anti-gp210 M-ANA and these autoantibodies appeared to be $100 \%$ specific for $\mathrm{PBC},{ }^{91}$ whereas in an American study $10 \%$ of patients with PBC reacted to recombinant gp $210 .^{90}$ Recent work has focused on the identification of the epitope(s) of gp210 recognised by M-ANA; one study has shown that PBC ANA react with a stretch of 15 amino acids in the cytoplasmic C-terminal domain..$^{92}$ Another study, using biochemically purified gp210, has demonstrated that anti-gp210 antibodies recognise at least two different epitopes, some reacting as above with the short cytoplasmic tail, whereas other sera react with a novel epitope within the large glycosylated luminal N-terminal domain $^{93}$ : carbohydrate moieties are an essential part of this novel epitope. The apparent discrepancy between these studies might be explained by the fact that bacterially expressed recombinant gp210 lacks, owing to the properties of the expression system, post-translational modification. This may also explain why only $10 \%$ of American patients with PBC appear to recognise recombinant gp $210^{90}$; some M-ANA might react only with the glycosylated $\mathrm{N}$-terminal domain of gp210 and fail to be detected. Two recent studies have used a recombinant protein or a synthetic polypeptide containing one immunodominant epitope of gp210 in ELISAs for the diagnosis of PBC ${ }^{94}{ }^{95}$; both ELISAs were highly specific for the clinical diagnosis of PBC (96\% and 99\%, respectively), and one study found these anti-gp210 autoantibodies in $47 \%$ of AMA negative patients with PBC. One small study suggested that the presence of anti-gp210 is associated with an increased risk of death from liver related causes. This finding has yet to be confirmed in larger series. ${ }^{96}$

Another glycoprotein of the nuclear pore complex, p62, has recently also been shown to be an autoantigen in about a third of patients with PBC. ${ }^{97}$ Again, carbohydrate moieties appear to participate in the immune recognition by M-ANA. Anti-p62 antibodies are highly specific for PBC but do not colocalise with anti-gp210 autoantibodies. Anti-gp210 and anti-p62 positivity appear, therefore, to identify distinct subgroups of patients. The clinical relevance of this observation, if any, remains unclear.

A very small subset of patients with $P B C$ have ANA reactive with an integral protein of the inner nuclear membrane, the lamin B receptor. ${ }^{98}$ Autoantibodies from four of these rare patients have been shown to recognise a conformational epitope contained within amino acids 1-60 of the nucleoplasmic N-terminal domain. ${ }^{99}$ So far, autoantibodies against the lamin $\mathrm{B}$ receptor also appear to be PBC specific and are more often present in the sera of patients who are AMA negative.

MND-ANA

PBC sera giving a multiple nuclear dot immunofluorescence pattern have been shown to bind to proteins of $95 \mathrm{kDa}^{100}$ and $78-92$ and $96-100 \mathrm{kDa}^{101}$ in immunoblots. Two nuclear proteins have now been shown to react with 
these MND-ANA. The first to be cloned was Sp $100 .^{102}$ This cDNA encodes a protein of unknown function with sequence similarities to several transcriptional transactivating proteins, including human immunodeficiency virus 1 (HIV-1) nef proteins. Large scale screening of anti-Sp 100 autoantibodies in sera from patients with various diagnoses has been performed by ELISA using recombinant proteins: anti-Sp100 antibodies were found in $27 \%$ (50 of 184) of patients with PBC, but in none of the patients with other liver diseases. Anti-Sp100 antibodies are occasionally found, however, in rheumatic disorders. Isotype differences in the anti-Sp100 response have been described between patients with PBC (who have $\operatorname{IgM}$ and $\operatorname{IgA}$ as well as $\operatorname{IgG}$ anti-Sp100) and patients with rheumatic disorders (IgG only), which might be helpful in discriminating between the underlying pathologies.

Epitope mapping experiments have shown that one domain of Sp100 (containing the sequence showing similarity with the HIV nef proteins) is recognised by all anti-Sp100 positive sera. ${ }^{103}$ Two major immunodominant epitopes have now been identified at amino acids $296-311$ and $332-351 .^{104}$ A second protein that colocalises to dot like nuclear domains, and which is aberrantly expressed in promyelocytic leukaemia cells (PML), has also been shown to react with MND-ANA in PBC sera. ${ }^{105}$ PML, as is the case with Sp100, shows sequence similarity with transcription factors, suggesting a possible role in transcription regulation. ${ }^{106}$ Interferons have been shown to increase the concentrations of both Sp100 and PML mRNA and protein. ${ }^{107}$ Autoantibodies against PML are as highly prevalent and specific for patients with PBC as those against Sp 100. ${ }^{105}$ Again, a single, and as yet unconfirmed, study has suggested that patients with PBC who are Sp100 and PML positive might have a worse prognosis than antibody negative patients (in this case, antibody positive patients were shown to be more likely to progress from early (stage I/II) to late disease (stage III/IV) over a follow up period of two years than anti-Sp100/anti-PML negative patients. ${ }^{108}$

The role played by all the PBC specific ANA in target cell damage is, as is the case with AMA, unclear. Anti-Sp100 and anti-gp20, as well as classic AMA persist post-liver transplantation, even in the absence of disease recurrence. ${ }^{109-111}$

\section{Non-M2 mitochondrial antigens}

It has been postulated by the Tubingen group that there are other mitochondrial antigens in addition to the M2 family that are important in PBC. The importance of the responses to these antigens and, indeed, the identities of the antigens themselves are controversial. Berg and colleagues initially described three antigens (M4, M8, and M9) associated with the outer mitochondrial membrane to which antibody responses are seen in PBC. ${ }^{112-114}$ Retrospective studies suggested that patients who were anti-M2 and anti-M9 positive at diagnosis had a relatively benign subsequent disease course, whereas patients who were anti-M4 and anti-M8 positive at presentation had a worse outcome. ${ }^{115}{ }^{116}$ A prospective study carried out by the same group has seemingly confirmed this finding. ${ }^{117}$ Although a serological marker predictive, at presentation, of the future disease course would be of the utmost value in the clinical management of patients, doubts remain about the importance of the data relating to anti-M4, anti-M8, and anti-M9. The greatest problem with regard to these studies is that they have not, as yet, been independently replicated. This is a result, in part, of the complex nature of the experimental approaches needed to detect these antibodies. Antibodies to M4, M8, and M9 are not detectable by standard immunofluorescence. Instead, detection requires the use of complement fixation or ELISA in the case of M4 and M8, and ELISA or immunoblotting in the case of M9. In the absence of positive identification of the M4, M8, and M9 antigens (early reports identifying M9 as glycogen phosphorylase ${ }^{118}$ and M4 as sulphite oxidase ${ }^{119}$ have not been confirmed $^{120}{ }^{121}$ ), fresh mitochondrial membrane preparations containing the relevant antigen fraction have to be used in the above assays. This drastically limits the extent to which these assays can be standardised between laboratories. The technical problems associated with the detection of anti-M4, antiM8, and anti-M9 antibodies, together with the uncertainties regarding the biochemical identity of the antigens, have led to the suggestion that the M4/M8/M9 nomenclature should be set aside pending clearer information on the character of these antigens and their disease associations. ${ }^{121}$ The potential clinical value of serological marker(s) predictive of prognosis, which would allow better targeting of treatments to high risk patients, is such that this area should be regarded as a priority for future research.

\section{Other antigens}

In addition to the well described responses to mitochondrial and nuclear autoantigens other autoantibody responses have been reported in PBC. One autoreactive response of potential clinical relevance is that directed against platelet specific antigens. Indeed, the inverse correlation between the titre of antiplatelet antibodies and platelet counts suggests that autoreactive antiplatelet responses contribute (together with non-autoimmune processes such as splenic pooling in patients with portal hypertension) to the thrombocytopenia see in PBC. ${ }^{122}$ It has been demonstrated recently that the antigens to which autoreactive antiplatelet responses are directed in PBC are the platelet glycoprotein complexes IIb-IIIa and Ib-IX. ${ }^{123}{ }^{124}$ Testing for antiplatelet antibodies remains a research tool at present, but the possibility of an autoimmune process should always be born in mind in patients with PBC suffering from thrombocytopenia. 


\section{Conclusions}

PBC is one of the autoimmune diseases with the best characterised serology. The recognition of the prevalence of autoantibody responses and subsequent identification of the important autoantigens has greatly contributed to our understanding of this disease. We are, however, still learning about the disease. Perhaps the most important new development in our understanding of the immunology of $\mathrm{PBC}$, as it relates to clinical practice, is our appreciation of the sheer scale of the association between the presence of the histological features of PBC and serum AMA and PBC specific ANA, and the concomitant value of these serological markers for clinical diagnosis. It is probably true to say that what in many ways represented the advent of our understanding of PBC, the observation that autoantibodies are present in the serum of patients with PBC remains, several decades later, the single most important phenomenon in the clinical management of the disease.

1 Neuberger JM. Primary biliary cirrhosis. Lancet 1997; 350:875-9.

2 Scheuer PJ. Primary biliary cirrhosis. Proc R Soc Med 1967 60:1257-61.

3 Metcalf JV, Bhopal RS, Gray J, et al. Incidence and prevalence of primary biliary cirrhosis in the city of 830-6.

4 Jones DEJ, James OFW, Bassendine MF. Primary biliary cirrhosis: clinical and associated autoimmune features and cirrhosis: clinical and associated autoimmune features

5 Cauch-Dudek K, Abbey S, Stewart DE, et al. Fatigue in primary biliary cirrhosis. Gut 1998;43:705-10.

6 James OFW, Bhopal R, Howel D, et al. Primary biliary cirrhosis once rare, now common in the UK? Hepatology 1999;30:390-4.

7 Neuberger J. Transplantation for primary biliary cirrhosis. Semin Liver Dis 1997;17:137-46.

8 Gross C, Malinchoc M, Kim W, et al. Quality of life before and after transplantation for cholestatic liver disease. Hepatology 1999;29:356-64.

9 Poupon RE, Balkau B, Eschwege E, et al. A multicenter, controlled trial of ursodiol for the treatment of primary biliary cirrhosis. UDCA-PBC study group. $N$ Engl $\mathcal{f} \mathrm{Med}$ 1991;324:1548-54.

10 Lindor KD, Dickson ER, Baldus WP, et al. Ursodeoxycholic acid in the treatment of primary biliary cirrhosis. Gastroenterology 1994;106:1284-90.

11 Combes B, Carithers RL, Jr, Maddrey WC, et al. A randomised, double-blind, placebo-controlled trial of ursodeoxycholic acid in primary biliary cirrhosis. Hepatology 1995;22:759-66.

12 Heathcote EJ, Cauch-Dudek K, Walker V, et al. The Canadian multicenter double-blind randomised controlled trial of ursodeoxycholic acid in primary biliary cirrhosis. Hepatology 1994;19:1149-56.

13 Mackay IR. Primary biliary cirrhosis showing a high titre of autoantibody: report of a case. $N$ Engl F Med 1958;258:185-8

14 Walker JG, Doniach D, Roitt IM, et al. Serological tests in the diagnosis of primary biliary cirrhosis. Lancet 1965;i: 827-31.

15 Berg PA, Klein R, Lindenborn-Fotinos J, et al. ATPaseassociated antigen (M2): marker antigen for serological diagnosis of primary biliary cirrhosis. Lancet 1982;ii: 1423-6.

16 Berg PA, Klein R, Lindenborn-Fotinos J. Antimitochondrial antibodies in primary biliary cirrhosis. $\mathcal{F}$ Hepatol 1986;2: 123-31.

17 Gershwin ME, Mackay IR, Sturgess A, et al. Identification and specificity of a cDNA encoding the $70 \mathrm{kD}$ mitochon-
drial antigen recognized in primary biliary cirrhosis. 7 drial antigen recognized in

18 Yeaman SJ, Fussey SP, Danner DJ, et al. Primary biliary cirrhosis: identification of two major M2 mitochondrial autoantigens. Lancet 1988;i:1067-70.

19 Van de Water J, Gershwin ME, Leung P, et al. The autoepitope of the $74-\mathrm{kD}$ mitochondrial autoantigen of primary biliary cirrhosis corresponds to the functional site of dihydrolipoamide acetyltransferase. $\mathcal{F}$ Exp Med 1988 167:1791-9.

20 Yeaman SJ. The 2-oxo acid dehydrogenase complexes: recent advances. Biochem f 1989;257:625-32.

21 Andersson SG, Zomorodipour A, Andersson JO, et al. The genome sequence of Rickettsia prowazekii and the origin of mitochondria. Nature 1998;396:109-10.

22 Perham RN. Domains, motifs and linkers in 2-oxo acid dehydrogenase multienzyme complexes: a paradigm in the
design of a multifunctional protein. Biochemistry $1991 ; 30$ : design of
23 Green JD, Laue ED, Perham RN, et al. Three-dimensional structure of a lipoyl domain from the dihydrolipoyl acetyltransferase component of the pyruvate dehydrogenase transferase component of the pyruvate dehydrogenase 248:328-43.

24 Howard MJ, Fuller C, Broadhurst RW, et al. Threedimensional structure of the major autoantigen in primary biliary cirrhosis. Gastroenterology 1998;115:139-46.

25 Palmer JM, Bassendine MF, James OFW, et al. Human pyruvate dehydrogenase complex as an autoantigen in primary biliary cirrhosis. Clin Sci 1993;85:289-93.

26 Palmer JM, Jones DEJ, Quinn J, et al. Characterisation of the autoantibody responses to recombinant $\mathrm{E} 3$ binding protein (protein X) of pyruvate dehydrogenase in primary biliary cirrhosis. Hepatology 1999;30:21-6.

27 Dubel L, Tanaka A, Leung P, et al. Autoepitope mapping and reactivity of autoantibodies to the dihydrolipoamide dehydrogenase-binding protein $(\mathrm{E} 3 \mathrm{BP})$ and the glycine cleavage proteins in primary biliary cirrhosis. Hepatology 1999:29:1013-18.

28 Robe AJ, Palmer JM, Yeaman SJ, et al. The E3BP (protein $\mathrm{X}$ ) component of pyruvate dehydrogenase complex (PDC) is not a T-cell autoantigen in primary biliary cirrhosis (PBC) [abstract]. $\mathcal{F}$ Hepatol 2000;32:29.

29 Fussey SPM, Bassendine MF, Fittes D, et al. The E1 $\alpha$ and $\beta$ subunits of the pyruvate dehydrogenase complex are M2"d" and M2" $\mathrm{e}$ " autoantigens in primary biliary cirrhosis. Clin Sci 1989;77:365-8.

30 Fussey SP, West SM, Lindsay JG, et al. Clarification of the identity of the major autoantigen in primary biliary cirrhosis. Clin Sci 1991;80:451-5.

31 Fussey SPM, Guest JR, James OFW, et al. Identification and analysis of the major M2 autoantigens in primary biliar cirrhosis. Proc Natl Acad Sci U S A 1988;85:8654-8.

32 Surh CD, Danner DJ, Ahmed A, et al. Reactivity of primary biliary cirrhosis sera with a human fetal liver cDNA clone of branched-chain a-keto acid dehydrogenase dihydrolipoamide acyltransferase, the $52 \mathrm{kDa}$ mitochondrial autoantigen. Hepatology 1989;9:63-8.

33 Mutimer DJ, Fussey SP, Yeaman SJ, et al. Frequency of IgG and IgM autoantibodies to four specific M2 mitochondrial autoantigens in primary biliary cirrhosis. Hepatology 1989; 10:403-7.

34 Fussey SP, Bassendine MF, James OFW, et al. Characterisation of the reactivity of autoantibodies in primary biliary

35 Fussey SPM, Bassendine MF, James OFW, et al. The lipoatecontaining domain of PDC E2 contains the main immunogenic region of the $70 \mathrm{kD}$ M2 autoantigen in primary biliary cirrhosis. Ann N Y Acad Sci 1989;573:444-6.

36 Fussey SP, Ali ST, Guest JR, et al. Reactivity of primary biliary cirrhosis sera with Escherichia coli dihydrolipoamide acetyltransferase (E2p): characterisation of the main immuno-

37 Surh CD, Coppel R, Gershwin ME. Structural requirement for autoreactivity on human pyruvate dehydrogenase-E2, the major autoantigen of primary biliary cirrhosis. F Immunol 1990;144:3367-74.

38 Tuaillon N, Andre C, Briand JP, et al. A lipoyl synthetic octapeptide of dihydrolipoamide acetyltransferase specifically recognised by anti-M2 autoantibodies in primary biliary cirrhosis. F Immunol 1992;148:445-50.

39 Quinn J, Diamond AG, Palmer JM, et al. Lipoylated and unlipoylated domains of human PDC-E2 as autoantigens in primary biliary cirrhosis: significance of lipoate attachment. Hepatology 1993;18:1384-91.

40 Thomson RK, Davis Z, Palmer JM, et al. Immunogenetic analysis of a panel of monoclonal IgG and IgM antibodies derived from patients with primary biliary cirrhosis. $f$ Hepatol 1998;28:582-94.

41 Harris RA, Bowker-Kinley MM, Wu P, et al. Dihydrolipoamide dehydrogenase-binding protein of the human pyruvate dehydrogenase complex. F Biol Chem 1997;272: 19746-51.

42 Leung PS, Chuang DT, Wynn RM, et al. Autoantibodies to BCOADC-E2 in patients with primary biliary cirrhosis recognize a conformational epitope. Hepatology 1995;22: $505-13$

43 Moteki S, Leung PS, Dickson ER, et al. Epitope mapping and reactivity of autoantibodies to the E2 component of 2 -oxoglutarate dehydrogenase complex in primary biliary cirrhosis using recombinant 2-oxoglutarate dehydrogenase complex. Hepatology 1996;23:436-44.

44 Koike K, Ishbashi $\mathrm{H}$, Koike M. Immunoreactivity of porcine heart dihydrolipoamide acetyl- and succinyl-transferases (PDC-E2, OGDC-E2) with primary biliary cirrhosis sera: characterisation of the autoantigenic region and effects of enzymatic delipoylation and relipoylation. Hepatology

45 Neuberger JM, Thomson R. PBC and AMA - what is the connection? Hepatology 1999;29:271-6

6 Hannan S, Davies ET, Hussain MJ, et al. Placental transfer of antimitochondrial antibody is associated with liver pathology. Hepatology 1999;30:472A.

47 Joplin R, Gordon Lindsay J, Johnson GD, et al. Membrane dihydrolipoamide acetyltransferase (E2) on human biliary epithelial cells in primary biliary cirrhosis. Lancet 1992; 339:93-4.

48 Van de Water J, Turchany J, Leung PS, et al. Molecular mimicry in primary biliary cirrhosis. Evidence for biliary epithelial expression of a molecule cross-reactive with pyruvate dehydrogenase complex-E2. F Clin Invest 1993; $91 \cdot 2653-64$ 
49 Joplin RE, Johnson GD, Matthews JB, et al. Distribution of pyruvate dehydrogenase dihydrolipoamide acetyltransferase (PDC-E2) and another mitochondrial marker in salivary gland and biliary epithelium from patients with primary biliary cirrhosis. Hepatology 1994;19:1375-80

50 Joplin R, Wallace LL, Lindsay JG et al. The human biliary epithelial cell plasma membrane antigen in primary biliary cirrhosis: pyruvate dehydrogenase X. Gastroenterology 1997;113:1727-33

51 Tsuneyama K, Van de Water J, Nakanuma Y, et al. Human combinatorial autoantibodies and mouse monoclonal antibodies to PDC-E2 produce abnormal apical staining of salivary glands in patients with co-existent primary biliary cirrhosis and Sjogrens syndrome. Hepatology 1994;20: 893-8.

52 Joplin RE, Johnson GD, Matthews JB, et al. Distribution of pyruvate dehydrogenase dihydrolipoamide acetyltrans-
ferase (PDC-E2) and another mitochondrial marker in salivary gland and biliary epithelium from patients with salivary gland and biliary epithelium from patients win
primary biliary cirrhosis. Hepatology 1994;19:1375-80.

53 Alercon-Segovia D, Ruiz-Arguelles A, Llorente L. Broken dogma: penetration of autoantibodies into living cells. Immunol Today 1995;17:163-4

54 Palmer JM, Jones DEJ, Doshi M, et al. Secretory IgA anti-PDC in primary biliary cirrhosis: a novel mechanism for tissue damage? Hepatology 1998;28:541A.

55 Reynoso-Paz S, Leung PSC, Van de Water J, et al. Evidence for a locally driven mucosal response and the presence of mitochondrial antigen in saliva in primary biliary cirrhosis. Hepatology 2000;31:24-9.

56 Malmborg AC, Shultz DB, Luton F, et al. Penetration and co-localization in MDCK cell mitochondria of IgA derived from patients with primary biliary cirrhosis. 7 Autoimmun 1998;11:573-80.

57 Mazanec MB, Kaetzel CS, Lamm ME, et al. Intracellular neutralization of virus by immunoglobulin A antibodies. Proc Natl Acad Sci U S A 1992;89:6901-5.

58 Yeaman SJ, Kirby JA, Jones DEJ. Autoreactive responses to pyruvate dehydrogenase complex in the pathogenesis of primary biliary cirrhosis. Immunol Rev 2000;174:238-49.

59 Van de Water J, Ansari A, Surh CD, et al. Evidence for the targeting by 2-oxo-dehydrogenase enzymes in the T-cell response of primary biliary cirrhosis. F Immunol 1991;146: 89-94.

60 Löhr H, Fleischer B, Gerken G, et al. Autoreactive liver-infiltrating $\mathrm{T}$ cells in primary biliary cirrhosis
recognise inner mitochondrial epitopes and the pyruvate recognise inner mitochondrial epitopes and the py
dehydrogenase complex. F Hepatol 1993;18:322-7.

61 Jones DEJ, Palmer JM, Yeaman SJ, et al. T-cell responses to the components of pyruvate dehydrogenase complex in primary biliary cirrhosis. Hepatology 1995;21:995-1002.

62 Van de Water J, Ansari A, Prindiville T, et al. Heterogeneity of autoreactive T-cell clones specific for the E2 componen of the pyruvate dehydrogenase complex in primary biliary cirrhosis. F Exp Med 1995;181:723-3.

63 Shimoda S, Nakamura M, Ishibashi H, et al. HLA DRB4 0101-restricted immunodominant T-cell autoepitope of pyruvate dehydrogenase complex in primary biliary cirrhosis: evidence of molecular mimicry in human autoimmune disease. 7 Exp Med 1995;181:1835-45.

64 Jones DEJ, Palmer JM, Yeaman SJ, et al. T-cell responses to native human proteins in primary biliary cirrhosis. Clin Exp Immunol 1997;107:562-8.

65 Agarwal K, Jones DEJ, Bassendine MF. Genetic susceptibility to primary biliary cirrhosis. Eur $\mathcal{F}$ Gastroenterol Hepatol 1999;11:603-6.

66 Palmer JM, Diamond AG, Yeaman SJ, et al. T-cell responses to the putative autoepitope in prin

67 Jones DEJ, Palmer JM, Yeaman SJ, et al. The time-course of bile duct lesion development in experimental autoimmune cholangitis (a mouse model of primary biliary cirrhosis). Hepatology 1999;30:318A

68 Jones DEJ, Palmer JM, Yeaman SJ, et al. Breakdown of tolerance to pyruvate dehydrogenase complex in experimental autoimmune cholangitis a murine model of primary biliary cirrhosis. Hepatology 1999;30:65-70

69 Jones DEJ, Palmer JM, Yeaman SJ, et al. Co-sensitisation with self- and homologous foreign-antigen as a mechanism of breakdown of self-tolerance in primary biliary cirrhosis Gut 1999;44:A61.

70 Heseltine L, Turner IB, Fussey SP, et al. Primary biliary cirrhosis: quantitation of autoantibodies to purified mitochondrial enzymes and correlation with disease progression. Gastroenterology 1990;99:1786-92.

71 Mitchison HC, Bassendine MF, Hendrick AM, et al. Positive antimitochondrial antibody but normal liver function tests: is this primary biliary cirrhosis? Hepatology 1986; tion tests: is

72 Metcalf JV, Mitchison HC, Palmer JM, et al. Natural history of early primary biliary cirrhosis. Lancet 1996;348:13991402 .

73 Roll J, Boyer JL, Barry D, et al. The prognostic importance of clinical and histological features in asymptomatic and symptomatic primary biliary cirrhosis. N Engl f Med 1983 308:1-7.

74 Christensen E, Crowe J, Doniach D, et al. Clinical pattern and course of disease in primary biliary cirrhosis based on analysis of 236 patients. Gastroenterology 1980;78: on analysis 46.

75 Kisand KE, Kisand KV, Karvonen AL, et al. Antibodies to pyruvate dehydrogenase in primary biliary cirrhosis: correlation with histology. APMIS 1998;106:884-92.
76 Van Norstrand MD, Malnchoc M, Lindor KD, et al. Quantitative measurement of autoantibodies to recombinant mitochondrial antigens in patients with primary biliary cirrhosis: relationship of levels of autoantibodies to disease progression. Hepatology $1997,25: 6-11$.

77 Omagari K, Rowley MJ, Whittingham S, et al. Autoantibodies to M2 mitochondrial autoantigens in normal human sera by immunofluorescence and novel assays. $\mathcal{F}$ Gastroenterol Hepatol 1996;11:610-16.

78 Van de Water J, Fregeau D, Davis P, et al. Autoantibodies of primary biliary cirrhosis recognize dihydrolipoamide acetyltransferase and inhibit enzyme function. 7 Immunol 1988;141:2321-4.

79 Fregeau DR, Davis PA, Danner DJ, et al. Antimitochondrial antibodies of primary biliary cirrhosis recognize dihydrolipoamide acyltransferase and inhibit enzyme function of the branched chain a-ketoacid dehydrogenase complex. $\mathcal{F}$ Immunol 1989;142:3815-19.

80 Fregeau DR, Prindiville T, Coppel RL, et al. Inhibition of a-ketoglutarate dehydrogenase activity by a distinct popuation of autoantibodies recognising dehydrolipoamide succinyltransferase in primary biliary cirrhosis. Hepatology 1990;11:975-9.

81 Teoh KL, Mackay IR, Rowley MJ, et al. Enzyme inhibitory autoantibodies to pyruvate dehydrogenase complex in primary biliary cirrhosis differ for mammalian, yeast and bacterial enzymes: implications for molecular mimicry. Hepatology 1994;19:1029-33.

82 Moteki S, Leung PS, Coppel R, L., et al. Use of a designer triple expression hybrid clone for three different lipoyl domains for the detection of antimitochondrial autoantibodies. Hepatology 1996;24:970-3.

83 Doniach D, Roitt IM, Walker JG, et al. Tissue antibodies in primary biliary cirrhosis, active chronic (lupoid) hepatitis, primary biliary cirrhosis, active chronic (lupoid) hepatitis,
cryptogenic cirrhosis and other liver diseases and their clinical implications. Clin Exp Immunol 1966;1:237-62.

84 Michieletti P, Wanless IR, Katz A, et al. Antimitochondrial antibody negative primary biliary cirrhosis: a distinct syndrome of autoimmune cholangitis. Gut 1994;35:260-5.

85 Lacerda MA, Ludwig J, Dickson ER, et al. Antimitochondrial antibody-negative primary biliary cirrhosis. Am $\mathcal{F}$ Gastroenterol 1995;90:247-9.

86 Heathcote EJ. Autoimmune cholangitis. Gut 1997;40:440-2.

87 Lozano F, Pares A, Borche L, et al. Autoantibodies against nuclear envelope-associated proteins in primary biliary cirrhosis. Hepatology 1988;8:930-8.

88 Lassoued K, Guilly MN, Andre C, et al. Autoantibodies to $200 \mathrm{kD}$ polypeptide(s) of the nuclear envelope: a new serologic marker of primary biliary cirrhosis. Clin Exp Immunol 1988;74:283-8.

89 Courvalin JC, Lassoued K, Bartnik E, et al. The 210-kD nuclear envelope polypeptide recognized by human autoantibodies in primary biliary cirrhosis is the major glycoprotein of the nuclear pore. F Clin Invest 1990;86:279-85.

90 Nickowitz RE, Wozniak RW, Schaffner F, et al. Autoantibodies against integral membrane proteins of the nuclear envelope in patients with primary biliary cirrhosis. Gastroenterology 1994;106:193-9.

91 Lassoued K, Brenard R, Degos F, et al. Antinuclear antibodies directed to a 200-kilodalton polypeptide of the nuclear envelope in primary biliary cirrhosis. A clinical and immunological study of a series of 150 patients with primary biliary cirrhosis. Gastroenterology 1990;99:181-6.

92 Nickowitz RE, Worman HJ. Autoantibodies from patients with primary biliary cirrhosis recognize a restricted region within the cytoplasmic tail of the nuclear pore membrane glycoprotein gp 210. ₹ Exp Med 1993;178:2237-42.

93 Wesierska-Gadek J, Hohenauer H, Hitchman E, et al. Autoantibodies from patients with primary biliary cirrhosis preferentially react with the amino-terminal domain of the nuclear pore complex glycoprotein gp210. ₹ Exp Med 1995;182:1159-62.

94 Tartakovsky F, Worman HJ. Detection of gp210 autoantibodies in primary biliary cirrhosis using a recombinant protein containing the predominant autoepitope. Hepatology 1995;21:495-500.

95 Bandin O, Courvalin JC, Poupon R, et al. Specificity and sensitivity of gp210 autoantibodies detected using an enzyme-linked immunoabsorbent assay and a synthetic polypeptide in the diagnosis of primary biliary cirrhosis. Hepatology 1996;23:1020-4.

96 Itoh S, Ichida T, Yoshida T, et al. Autoantibodies against a $210 \mathrm{kDa}$ glycoprotein of the nuclear pore complex as a prognostic marker in patients with primary biliary cirrhoprognostic marker in patients with primary
sis. $\mathcal{F}$ Gastroenterol Hepatol 1998;13:257-65.

97 Wesierska-Gadek J, Honenauer H, Hitchman E, et al. Autoantibodies against nucleoporin p62 constitute a novel marker of primary biliary cirrhosis. Gastroenterology 1996; 110:840-7.

98 Courvalin JC, Lassoued K, Worman HJ, et al. Identification and characterisation of autoantibodies against the nuclear envelope lamin B receptor from patients with primary biliary cirrhosis. f Exp Med 1990;172:961-7.

99 Lin F, Noyer CM, Ye Q, et al. Autoantibodies from patients with primary biliary cirrhosis recognize a region within the LBR. Hepatology 1996;23:57-61.

100 Evans J, Rueben A, Craft C. PBC95K, a 95 kilodalton nuclear autoantigen in primary biliary cirrhosis. Arthritis Rheum 1991;34:731-6.

101 Fusconi M, Cassani F, Govoni M, et al. Anti-nuclear antibodies of primary biliary cirrhosis recognise $78-92-\mathrm{kD}$ and 96-100-kD proteins of nuclear bodies. Clin Exp Immunol 1991;83:291-7. 
102 Szostecki C, Guldner HH, Netter HJ, et al. Isolation and characterisation of cDNA encoding a human nuclear antigen predominantly recognised by autoantibodies from patients with primary biliary cirrhosis. F Immunol 1990 145:4338-47.

103 Szostecki C, Will H, Netter HJ, et al. Autoantibodies to the nuclear $\mathrm{Sp} 100$ protein in primary biliary cirrhosis and associated diseases: epitope specificity and immunoglobulin class distribution. Scand F Immunol 1992;36 555-64.

104 Bluthner M, Schafer C, Schneider C, et al. Identification of major linear epitopes on the sp100 nuclear autoantigen of the 1999;29:33-42.

105 Sternsdorf T, Gulder HH, Szostecki C, et al. Two nuclear dot associated proteins, PML and Sp100, are often
co-autoimmunogenic in patients with primary biliary co-autoimmunogenic in patients with primos
cirrhosis. Scand $\mathscr{7}$ Immunol 1995;42:257-68

106 Kakizuka A, Miller WHJ, Umesono K, et al. Chromosomal translocation $\mathrm{t}(15: 17)$ in human promyelocytic leukaemia fuses RARa with a novel putative transcription factor, PML. Cell 1991;66:663-74.

107 Grotzinger H, Sternsdorf T, Jensen K, et al. Interferonmodulated expression of genes encoding the nuclear-dotassociated proteins $\mathrm{Sp} 100$ and promyelocytic leukemia protein (PML). Eur f Biochem 1996;238:554-60.

108 Zuchner D, Stersdorf T, Szostecki C, et al. Prevalence, kinetics, and therapeutic modulation of autoantibodies against Sp100 and promyelocytic leukemia protein in a large cohort of patients with primary biliary cirrhosis Hepatology 1997;26:1123-30.

109 Luettig B, Boeker KH, Schoessler W, et al. The anti-nuclear autoantibodies Sp100 and gp210 persist after orthotopic liver transplantation in patients with primary biliary cirrhosis. $\mathcal{F}$ Hepatol 1998;28:824-8.

110 Dubel L, Farges O, Courvalin JC, et al. Persistence of gp210 and multiple nuclear dot antibodies does not correlate with recurrence of primary biliary cirrhosis 6 years after liver transplantation. ₹ Hepatol 1998;28:169-70.

111 Mattalia A, Luttig B, Rosina F, et al. Persistence of autoantibodies against recombinant mitochondrial of autoantibodies against recombinant mitochondrial tation for primary biliary cirrhosis. $\mathcal{F}$ Autoimmun $1997 ; \mathbf{1 0}$ tation for-7.

112 Berg PA, Klein R, Lindenborn-Fotinos J. Antimitochondrial antibodies in primary biliary cirrhosis. $f$ Hepatol $1986 ; 2: 123-31$
113 Weber P, Brenner J, Stechemesser E, et al. Characterisation and clinical relevance of a new complement fixing antibody-anti-M8 - in patients
rhosis. Hepatology 1986;6:553-9.

114 Klein R, Berg PA. Characterisation of a new antigenantibody system (M9/anti-M9) in patients with anti M2-positive and anti M2-negative primary biliary cirrhosis. Clin Exp Immunol 1988;74:68-74.

115 Klein R, Kloppel G, Garbe W, et al. Anti-mitochondrial antibody profiles determined at early stages of primary bilary cirrhosis differentiate between a benign and a progressive course of the disease: a retrospective analysis of 76 patients over 6-18 years. F Hepatol 1991;12:21-7.

116 Klein R, Huizenga JR, Gips CH, et al. Antimitochondrial antibody profiles in patients with primary biliary cirrhosis before orthotopic liver transplantation and titers of AMAsubtypes after transplantation. F Hepatol 1994;20:181-9.

117 Klein R, Pointner H, Zilly W, et al. Antimitochondrial antibody profiles in primary biliary cirrhosis distinguish at early stages between a benign and a progressive course: a prospective study on 200 patients followed for 10 years. prospective study on

118 Klein R, Berg PA. Anti M9 antibodies in sera from patients with primary biliary cirrhosis recognise an epitope of glycogen phosphorylase. Clin Exp Immunol 1990;81:65-71.

19 Klein R, Berg PA. Anti-M4 antibodies in primary biliary cirrhosis react with sulphite oxidase, an enzyme of the mitochondrial inner membrane space. Clin Exp Immunol 1991;84:445-8.

120 Palmer JM, Yeaman SJ, Bassendine MF, et al. M4 and M9 autoantigens in primary biliary cirrhosis - a negative study. 7 Hepatol 1993;18:252-4.

121 Davis PA, Leung P, Manns M, et al. M4 and M9 antibodies in the overlap syndrome of primary biliary cirrhosis and chronic active hepatitis: epitopes or epiphenomena? Hepatology 1992;16:1128-37.

122 Basseendine MF, Collins JD, Stephenson, J, et al. Platelet associated immuno-globulins in primary biliary cirrhosis: a cause of thrombocytopenia. Gut 1985;26:1074-9.

123 Panzer S, Penner E, Nelson PJ, et al. Identification of the platelet glycoprotein IIb/IIIa as a target antigen in primary biliary cirrhosis-associated autoimmune thrombocytopenia. Evidence that platelet-reactive autoantibodies can also bind to the mitochondrial antigen M2. F Autoimmun 1990; 3:473-83.

24 Feistauer SM, Penner E, Mayr WR, et al. Target platelet antigens of autoantibodies in patients with primary biliary cirrhosis. Hepatology 1997;25:1343-5. 